\title{
Gide em pauta
}

Alain Goulet

A morte de Gide só nos diz respeito porque sua vida nos diz respeito, e sua vida só nos interessa porque produziu uma obra, uma obra importante, singular, irredutível, necessária. Gide precisava escrever para viver, para se desenvolver, para progredir, provar-se e circunscrever uma identidade sempre incerta e movente. Como afirma Edouard em Les faux-monnayeurs $[$ Os moedeiros falsos], qualificado de Proteu, assim como às vezes o próprio autor:

Eu nunca sou apenas aquilo que creio ser - e isto varia o tempo todo, de forma que, muitas vezes, se eu não estivesse lá para aproximá-los, meu ser da manhã não reconheceria o da noite. Não há nada mais diferente de mim do que eu mesmo. [...] Meu coração só bate por simpatia; vivo apenas por outrem; por procuração, poderia dizer, por núpcias, e é quando saio de mim mesmo para me tornar qualquer um que sinto viver mais intensamente que nunca*.
Je ne suis jamais ce que je crois que je suis - et cela varie sans cesse, de sorte que souvent, si je n'étais là pour les accointer, mon être du matin ne reconnaîtrait pas celui du soir. Rien ne saurait être plus différent de moi, que moi-même [...]. Mon cœur ne bat que par sympathie; je ne vis que par autrui; par procuration, pourrais-je dire, par épousaille, et ne me sens jamais vivre plus intensément que quand je m'échappe à moi-même pour devenir n'importe qui.
*Gide, A. "Les faux-
monnayeurs. Em: Romans,
récits et soties, œuvres
lyriques. "Bibliothèque de
la Pléiade". Paris: Gallimard,
1958: 987)

Como seu personagem, Gide sente viver "por outrem; por procuração", por e para sua obra, sendo sobretudo "outrem" os personagens nascidos de um "botão" dele mesmo, segundo um método próprio explicitado em L'immoraliste [O imoralista]:

Quantos botões temos em nós [...], que só rebentarão nos livros! São "olhos adormecidos", como os chamam os botânicos. Mas se, por vontade própria, suprimimos todos menos um, como ele cresce rápido, como se desenvolve e se apossa da seiva! Para
Que de bourgeons nous portons en nous [...], qui n'écloront jamais que dans nos livres! Ce sont des "oeils dormants" comme les nomment les botanistes. Mais si, par volonté, on les supprime tous, sauf un, comme il croît aussitôt, comme il grandit! comme aussitôt 
"(Gide, A. "Lettre à Scheffer". Em: CEuvres complètes, to mo 4, NRF, 1933: 616.7)

- "Nous devons tous repré. senter" (Gide, A. Si le grain ne meurt, em Journal 1939 1949. Souvenirs. "Biblio thèque de la Pléiade". Paris: Gallimard, 1954: 542)

- "Tout phénomène est le Symbole d'une Vérité. Son seul devoir [à l'artiste] est qu'il la manifeste. [...] Nous vivons pour manifester" (Gide, A. "Le traité du Nar. cisse" (1891). Em: Romans, récits et soties, œuvres lyriques. Op. cit: 8 )

“ “Il s'intéressait à la vie, [...] dès son enfance il avait fait de sa vie une chose sé rieuse, importante, motif de culture et de perfection, objet d'une contemplation passionnée" (Copeau, J. "2 de julho de 1905". Em: Journal 1901-1915. Paris: Seghers, 1991: 211)

\footnotetext{
- "opiniâtreté [...] à pro. fesser une foi unique: que toute vérité, même triste, même sulfureuse, même dangereuse, est bonne à dire et à instruire" (Ozouf, M. "M. Gide voyage". Em: Le Nouvel Observateur, $n^{\circ} 1898$, 22.28 março, 2001: 138)
}

criar um herói minha receita é il s'empare de la sève! Pour créer un simples: tome um desses botões, héros ma recette est bien simple: ponha-o numa panela - só ele-, Prendre un de ces bourgeons, le e logo se chega a um indivíduo mettre en pot-tout seul-on arrive admirável. Conselho: escolher de bientôt à un individu admirable. preferência (se é verdade que po- Conseil: choisir de préférence (s'il demos mesmo escolher) o botão est vrai qu'on puisse choisir) le que mais incomoda você. Assim, bourgeon qui vous gêne le plus. On desfaz-se dele de uma vez só. Tal- s'en défait du même coup. C'est vez seja isto que Aristóteles cha- peut-être là ce qu’appelait Aristote: mava de purificação das paixões. la purgation des passions. ${ }^{*}$

Bem cedo, ele se sentiu escolhido. Ou seja, não somente viver, para ele, passava necessariamente pela escrita, mas consideravase investido de uma missão: "Todos nós devemos representar"*, proclamou com orgulho ao se engajar na carreira de escritor, fórmula que se tornaria, em seu Le traité $d u$ Narcisse $[O$ tratado de Narciso], "Nós vivemos para manifestar": "Todo fenômeno é o Símbolo de uma Verdade. Seu único dever [do artista $]$ é manifestá-la. [...] Nós vivemos para manifestar".

A perenidade de Gide e sua importância parecem dever-se principalmente ao engajamento resoluto e constante em sua obra, que é ainda mais perceptível se pensarmos que ele, longe de limitar-se a uma obra específica ou às circunstâncias da época, a vê em sua totalidade, no conjunto desse organismo vivo que se desenvolveu consubstancialmente ao escritor e ao sabor das necessidades de sua progressão pessoal, ao mesmo tempo provocada e acompanhada pela obra.

Finalmente, devem-se também a seu partido constante pela vida e pela verdade, enfatizado tanto por Jacques Copeau: "Ele se interessava pela vida [...] desde a infância, para ele a vida era algo sério, importante, razão para se cultivar e aperfeiçoar, objeto de uma apaixonada contemplação"*, quanto por Mona Ozouf, que celebra, no final de seu recente comentário da reedição de Souvenirs et voyages, sua "obstinação [...] em professar uma fé única: que toda verdade, mesmo triste, mesmo sulfurosa, mesmo perigosa, serve para ser dita e para instruir"*.

\section{I}

Comecemos, portanto, por considerar o desenvolvimento dessa obra consubstancial a seu autor. 
Antes de tudo, Gide lançou-se à escrita de um Diário, concebido como uma compilação das concreções da vida e também como matriz da obra, algo como uma peneira entre a vida e a obra. Sabemos que ele manteria tal prática até sua morte, às vezes com inflexões específicas devido às circunstâncias, como o Journal du Foyer franco-belge, durante a Primeira Guerra Mundial (de 19 de outubro de 1914 até 1916), ou Voyage au Congo [Viagem ao Congo], ou ainda Retour de l'URSS [Volta da URSS] - que tratam de aventuras particulares cujo alcance o ultrapassa e de que ele é uma grande testemunha -; o Journal des faux-monnayeurs [Diário dos moedeirosfalsos] - que desvenda os bastidores da criação literária para além do romance em questão, por refletir sobre o gênero do romance em geral -, ou Ainsi soit-il, que prolonga o Diário, obra em que ele tenta até o último momento descobrir em si o que resta a dizer e ainda não foi dito.

Do Diário passa-se à criação literária propriamente dita, que com freqüência leva sua marca, como a de uma origem controlada; mas a presença de um diário em uma obra vai bastante além, por tornar-se, em seu cerne, o espaço de uma reflexão distanciada, como em Les cahiers d'André Walter ou Les faux-monnayeurs.

Vejamos então como essa criação literária se desenvolveu e amadureceu com a evolução de Gide.

Esquematicamente, eu poderia distinguir cinco fases. Na primeira, o escritor é como uma mônada solitária e há uma busca de si, voltada para questões como identidade e sentido tanto da vida como da obra, fase que iria desde os neo-românticos Les cahiers d'André Walter (1891) [Cadernos de André Walter] até a exaltação de Les nourritures terrestres (1897) [Os frutos da terra], que assinala um novo nascimento. Nesta fase, Gide se projeta sob a forma de um alter ego, tal como em Les cahiers d'André Walter, vendo-se como o último avatar do Poeta encarregado de reparar os erros de Adão e Narciso, trabalhando pela salvação da humanidade*, ou como Urien*, cavaleiro que luta para conquistar um fabuloso extremo, uma certeza que fundaria o sentido da vida e da obra, o que finalmente engendra nada mais que o vazio. Esta primeira fase, de "tratados" e lirismo, permite que se reconheça, que teste sua vocação, seus valores e seu projeto, no sentido sartriano do termo.

A segunda fase é a das "narrativas" e do teatro, em que Gide se abre ao outro e à realidade do mundo, de Les nourritures

\footnotetext{
" (Gide, A. "Le traité du Narcisse". Em: Romans, récits et soties, œuvres lyriques, Op. cit.)

" (Gide, A. "Le voyage d'Urien" (1893). Em: Ro. mans, récits et soties, œuvres lyriques. Op. cit)
} 
" (Gide, A. "La porte étroite" (1909). Em: Romans, récits et soties, œurres lyriques. Op. cit.) terrestres a La porte étroite ${ }^{*}$ [A porta estreita]. Nessa fase, as questões morais se adiantam aos problemas metafísicos; tais questões se debatem, se provam, se criticam. Por exemplo, através de Michel, em L'immoraliste, Gide experimenta a possibilidade de repudiar em si o novo homem, fruto da educação e do condicionamento social, e fazer renascer o velho homem, o homem natural, com seus desejos e pulsões. Mas a desordem e a falta de desestruturação do Ego espreitam o imoralista, tal como Saul, o herói da peça epônima.

Vem então uma terceira fase, romanesca, a da verdadeira maturidade da obra, caracterizada por uma observação e uma experimentação crítica do mundo e da sociedade, desde Isabelle (1911) até Les faux-monnayeurs (1925). É também a fase em que nasce e se precisa o projeto autobiográfico central, o de Si le grain ne meurt [Se o grão não morre]. Portanto, para nosso romancista, trata-se de observar a sociedade contemporânea, as forças e as modalidades de comportamento individuais ou coletivas, de ter domínio sobre a realidade social e humana - e, por outro lado, chegar a se dizer, a afirmar o que se é. O que determina o comportamento dos indivíduos? No que cada um é condicionado ou determinado pelo meio? De que maneira a liberdade individual pode se exercer, e quais seriam seus limites? De forma sintomática e sistemática, Les caves du Vatican [Os subterrâneos do Vaticano], por exemplo, opõe tipos, marionetes que se caracterizam por consolações ideológicas (Anthime, Julius, Amédée), a um Lafcadio encarregado de testar as possibilidades de uma fuga dos condicionamentos sociais por ser bastardo e uma educação que resolutamente volta as costas para o aprendizado escolar e social, sobretudo o da época.

Depois de Les faux-monnayeurs, Gide sente ter enfim encerrado seu programa de criações, ficções e ensaios, que o habitava desde a juventude. Ele se afirmou, soube defender e ilustrar a causa da homossexualidade por três obras complementares, Corydon, Si le grain ne meurt e Les faux-monnayeurs, além de escrever um romance verdadeiramente novo e que concentra toda a sua experiência e filosofia da vida social. Enfim, atingiu o sucesso, tornou-se “o contemporâneo capital” e quis se perder um pouco de vista: parte para a África negra com um "cansaço de ser Gide”. Mas, como sabemos, nesse país ele foi apanhado pela necessidade de falar sobre e testemunhar exigências absurdas, escândalos e horrores dos quais se torna depositário, de 
denunciar os malfeitos da colonização. Vem então o quarto tempo, o do testemunho e engajamento social e político. Nosso "contemporâneo capital” se torna um "intelectual” lançado à arena política, cuja foto na Praça Vermelha, ao lado de Stálin, nas exéquias de Gorki, faria a volta ao mundo. Na lógica de suas constatações e de sua aspiração a uma outra sociedade, o antigo discípulo de Mallarmé soube ir até o fim em seu engajamento. Até o fim, ou seja, soube igualmente fazer o caminho de volta ao sentir ter sido usado para uma causa que se revelou falsa: onde esperava a liberdade humana, encontrou um espírito de vassalagem. É o famoso Retour de l'URSS, seguido de Retouches (1936-37).

Após 1937, vem a fase de um relativo desengajamento ou, mais exatamente, de uma sabedoria conquistada e de análise, análise de uma vida e de uma obra que tiveram Teseu como símbolo: "Para o bem da humanidade futura, fiz minha obra. Vivi"*"

É com essas palavras que se encerra esta obra, recebida em geral como testamentária.

\section{II}

Após este rápido esboço do percurso de uma vida que se confunde com a realização da obra (e vice-versa), podemos nos voltar para algumas grandes questões que dominaram o pensamento e o trabalho do escritor.

A primeira, mais vasta e mais constante, foi sem dúvida o status e o lugar do Ego: como se conhecer, estar a uma fina escuta de si e na exigência de si, dispor de si sem se desviar ou se perder? Conhecemos a famosa frase que abre L'immoraliste: "Saber se libertar não é nada; árduo é saber ser livre"*.

Gide se ocupou principalmente da liberação daquilo que sentia como determinações exteriores, induzidas, pesadas, da família, da educação, da religião, da moral, da sociedade, para chegar à livre disposição de si. Em Les nourritures terrestres, elabora um evangelho lírico da disponibilidade no instante, instante cortado das determinações do passado, para se concentrar nas sensações, nos sentimentos, no "fervor" e nos élans do presente. Em Nouvelles nourritures, 38 anos depois, ele resumiria essa profunda aspiração à liberação completa de si com as palavras: "Tábula rasa. Varri tudo. Está feito! Ergo-me nu sobre a terra virgem, diante do céu a repovoar"**

Gide se opõe resolutamente a tudo o que entrava, determina o indivíduo e o torna tributário a uma pessoa, causa ou insti-
" "Pour le bien de l'humanité future, j'ai fait mon œuvre. J'ai vécu" (Gide, A. "Thésée". Em: Romans, récits et soties, œuvres lyriques. Op. cit.: 1453)

" "Savoir se libérer n'est rien; I'ardu, c'est savoir être libre" (: 372).

" "Table rase. J'ai tout balayé. C'en est fait! Je me dresse nu sur la terre vierge, devant le ciel à repeupler" (: 255). 
- "Ne te méprends pas, Nathanaël, au titre bruta qu'il m'a plu de donner à ce livre [...]" (:153).
- (Cf. Goulet, A. "L'écriture de l'acte gratuit". Em:André Gide n6, 1979:177.201)

\footnotetext{
- "Je vivais inconscient; j'ai tué comme dans un rêve; un cauchemar où, depuis, je me débats... (Gide, A. "Les caves du Vatican". Em: Romans, récits et soties, œurres lyriques, Op. cit.: 871).

- "Il est bon de suivre sa pente, pourvu que ce soit en montant" (Gide, A. Les faux monnayeurs". Em: Romans, récits et soties, œuvres lyriques, Op. cit.: 1215).
}

tuição que não reconheça como suas. Podemos hoje nos surpreender com as palavras de abertura a Les nourritures terrestres: "Não se engane, Nathanaël, com o título brutal que me agradou dar a este livro [ ...]"*.

Gide tem então consciência de operar em si uma revolução: os alimentos da Natureza substituíram, para ele, os alimentos celestes e os alimentos de uma cultura. O presente da vida e do instante se pôs no lugar de um além que se revelou quimérico. À sua maneira, $\mathrm{o}$ anti-Barrès que se levanta contra a doutrina das raízes e do enraizamento se une ao "culto do Ego"; ele se torna adepto de um egotismo atento à idiossincrasia de cada um, de alimentos pilhados ao sabor de um instante, de seus gostos e desejos.

Mas ele logo compreende que se trata apenas de uma etapa, e que "árduo é saber ser livre". A mônada se torna nômade, e o caminho é estreito entre o "nomadismo" que celebra e a errância e a perdição que serão o lote de Saul, Michel ou Vincent. Pois as narrativas, tanto o romance quanto o teatro, são o lugar de um debate moral permanente, dominado pelo problema da liberdade de ser, inseparável da consciência dos perigos que espreitam por todo lado. E logo a questão da liberação pessoal e da liberdade encontra seus limites em uma questão anexa, recorrente, e que se destaca de sotia em sotia: a concepção e a validez de um "ato livre" ou "gratuito".

$\mathrm{O}$ ato é mencionado em Paludes, no breve relato da "supressão" do "homem normal" por Valentin Knox, "sem remorsos, já não trazia nada de novo"*. Ressurge em Le Prométhée mal enchaîné [Prometeu mal acorrentado], lançado e estruturado de maneira profunda, pois este atributo de Zeus, o "Miglionnaire", sobre o qual teoriza o garçom, determina os destinos de Damocles, Cocles e, conseqüentemente, de Prometeu, que acaba matando a águia. Mas é em Les caves du Vatican que ele se torna mais claramente a pedra de toque da verdadeira liberdade* - que deve ter como correlato o senso de responsabilidade com relação ao outro e a si mesmo, não podendo se exercer em uma denegação do outro e da sociedade na qual sempre estamos inseridos, conscientes disso ou não. No fim, Lafcadio reconhece: "Eu vivia inconsciente; matei como em um sonho; um pesadelo em que, desde então, eu me debato..."*.

Enquanto Edouard enunciaria sua grande regra, que poderia lhe ter servido de garantia contra a loucura: "É bom acompanhar a própria queda, desde que seja para cima"* 
Outra grande questão na obra de André Gide é a do direito à sexualidade. Antecipando as teorias de Wilhelm Reich sobre a liberação da sexualidade das crianças, vítimas de uma família que funciona como "fábrica de ideologias autoritárias e estruturas mentais conservadoras", a obra caminha a partir da denegação e da repressão do desejo, desde Les cahiers d'André Walter a Voyage d'Urien, até o veemente protesto do escritor sobre o direito de viver segundo sua natureza: "Em nome de que Deus, de que ideal você me proíbe de viver segundo a minha natureza?”*

É sua exclamação no início da segunda parte de Si le grain ne meurt, preparando com essas palavras a revelação de uma homossexualidade vivida e assumida na alegria - a tal ponto que a palavra "alegria” ("joie”) torna-se quase sempre, no Diário, indicativo de uma plenitude e uma harmonia proporcionadas pela troca ou pela paixão homossexuais. Por isto as afirmações, em 1917, época do entusiasmo por Marc Allégret: "Maravilhosa plenitude de alegria", "perdido de alegria”; "o estado de alegria em que vivi por mais de um mês sem dúvida me fortaleceu e me fez recobrar a confiança”**.

Em seguida à experiência tunisiana de 1893 , Gide de fato insinuou a questão da homossexualidade em suas obras, mas de forma lateral e equívoca, como em Saül ou L'immoraliste, antes de aventurar-se a afirmá-la mais claramente em Les caves du Vatican, para o grande escândalo de Claudel. Mas seria preciso esperar o drama das cartas queimadas por Madeleine, em 1918, para que o escritor se sentisse desencumbido do dever de se reservar por causa de sua mulher e ousasse fixar como eixo de suas memórias a história de sua homossexualidade, a reconciliação por ela proporcionada e o verdadeiro novo nascimento que o reconciliou com sua natureza.

É necessário, portanto, considerar Si le grain ne meurt a segunda face, autobiográfica, de um manifesto cuja primeira face é Corydon, com uma primeira versão que ensaia seu aparecimento em 1911, mas só seria realmente publicada em 1924. Já a primeira edição integral de Si le grain ne meurtsó ganharia as livrarias em 1926, após o retorno do grande périplo na África negra. Diferentemente de Rousseau, Gide não pretendeu lançar-se a confissões, e ainda menos escrever "por penitência" como afirma ironicamente na abertura da obra - ou manifestar uma mítica inocência infantil. Ao contrário, e de saída, ele postula uma sexualidade infantil original, acumulando nas primei-
" "fabrique d'idéologies au. toritaires et de structures mentales conservatrices"

" "Au nom de quel Dieu, de quel idéal me défendez vous de vivre selon ma nature?" (Gide, A. "Si le grain ne meurt". Em: Journal 1939 1949. Souvenirs. Biblio thèque de la Pléiade. Paris: Gallimard, 1954: 550).

" "Merveilleuse plénitude de joie"; "tout éperdu de joie"; "l'état de joie dans lequel j'ai vécu plus d'un mois m'a fortifié sans doute et m'a redonné confiance"

" "par pénitence" 
- "A cet âge innocent où l'on voudrait que toute l'âme ne soit que transparence, tendresse et pureté, je ne revois en moi qu'ombre, laideur, sournoiserie".

" "Une photographie de ce temps, que je retrouve, me représente, blotti dans les jupes de ma mère, affublé d'une ridicule petite robe à carreaux, l'air maladif et méchant, le regard biais" (Gide, A. "Si le grain ne meurt". Em: Journal 1939 1949. Souvenirs. "Bibliothè que de la Pléiade". Paris: Gallimard, 1954: 349-50)

" "et si le diable me dupait en me faisant considérer comme une injure l'idée d'y pouvoir mêler quoi que ce fût de charnel, c'est ce dont je ne pouvais encore me rendre compte" (: 551-2).

- "tourner le dos à la réalité"; "Je fus sauvé par gourmandise..."] (: 535).

- "Que dirai-je choses véri. tables. - AUTRUI - impor. tance de sa vie; lui parler..." (Gide, A. "Les nourritures terrestres". Em: Romans, récits et soties, œuvres lyriques, Op. cit.: 246).

- "tout dévoré de sympa. thie" (Gide, A. Journal 1889 1939, 9 de outubro. "Biblio. thèque de la Pléiade". Paris: Gallimard, 1915: 511). ras páginas imagens sombrias de si mesmo: "Nessa idade inocente em que se deseja a alma toda transparência, ternura e pureza, em mim só contemplo sombra, feiúra, dissimulação"**

Afirma ele, antes de construir este auto-retrato em forma de requisitório: "Reencontro uma fotografia representativa do que eu era nessa época, enroscado na saia da mãe, enfiado em um ridículo vestidinho xadrez, um ar doentio e mau, o olhar de viés"*.

É a esta juventude sombria e desdenhada que ele oporia a luz de sua aquiescência à homossexualidade, encobrindo o princípio que havia feito estremecer sua juventude: a revelação de seu amor por Madeleine. Pois, a ponto de revelar seu maravilhamento pederástico, ele registra esta reflexão sobre seu "amor quase místico" pela prima: "e se o diabo me enganava, fazendome considerar uma injúria a idéia de insinuar nele algo carnal, fosse o que fosse, eu ainda não podia percebê-lo"* .

Foi seu modo de relativizar, e até mesmo de questionar, o que de início havia celebrado como o "oriente místico" de sua vida.

Outro fio condutor do desenvolvimento da obra gideana é o acesso à realidade daquele que havia começado por "virar as costas para a realidade". Mas acrescenta: "Fui salvo pela gula..."*.

Acesso ao outro, sobretudo. No início, o mundo de André Walter é estranhamente deserto, e seus Cahiers se organizam como um complexo jogo de espelhos que multiplicam sua imagem. Quando a "gula" o leva a optar pelos alimentos terrestres, seu mundo é despovoado, e o livro termina com esta constatação angustiada: "O que direi coisas verdadeiras. - OUTRO - importância de sua vida; falar com ele..."*.

$\mathrm{O}$ acesso ao outro, o verdadeiro outro, não foi tão fácil para ele, apesar de dizer-se "devorado de simpatia" ${ }^{*}$. Julgue-se pelos mal-entendidos reinantes entre os dois membros dos casais, desde André Walter-Emmanuèle, Urien-Ellis, o narrador de Paludes e Angèle, Michel et Marceline, Jérôme et Alissa... e sabemos que a lista se prolonga. Considere-se a maneira com que Gérard se fecha em seu sonho de uma mítica Isabelle antes de ser desenganado e chocado pela realidade da pessoa.

Para Gide, o outro seria por muito tempo a impossível companhia desejada, mas que afasta de si e abandona, as mulheres amadas e evitadas de L'immoraliste e La porte étroite, relatos de

\footnotetext{
${ }^{1}$ A expressão data, portanto, da época do Foyer franco-belga.
} 
encontros perdidos ou abortados. À margem desses casais que jamais se encontram, o escritor enfatiza a potência de um outro atrativo que poderia tomar a forma de diversos rostos, instituir uma relação pedagógica, segundo a teoria pregada no final de Corydon, ou excitar a sensualidade. De um lado, a escuta do mestre Ménalque, do outro, o desejo suscitado por Moktir, Charles ou Alcide. Mas seria preciso esperar Caves, e mais ainda Lesfauxmonnayeurs, para que o mundo se abrisse e se povoasse com uma verdadeira sociedade, e que o romancista se tornasse o divertido e sábio cronista da apresentação de um microcosmo.

$\mathrm{O}$ acesso à realidade é algo ainda mais complexo. Pois, desde sua primeira juventude, Gide se apega a esta convicção: "Há realidade e há sonhos; e há também uma segunda realidade”." Essa segunda realidade é a que os "Schaudern" " desvelam furtivamente - que têm relação estreita com a criação literária, "o estado lírico [...] em que Dionísio me visitava”, diz Gide -; é também "a invisível realidade"* na rua de Lecat. Enfim, é o que deixa o romancista perplexo e fascinado diante da estranheza e dos dramas da prodigiosa realidade social. Em seu "primeiro começo de Caves", trata-se de uma verdadeira conversão à observação e à consciência da realidade que é proclamada, mas uma realidade secreta que é posta à luz.

O que eu mais admiro na vida é seu formidável modo de atulhar a vista. A vida é como as florestas tropicais onde a abundância inextricável de galhos se opõe à claridade do dia. Esbarramos o tempo todo com fauna ou flora. Só saberíamos pousar os olhos em dramas; só conseguiríamos andar criando. Não há homem que, se não os viveu, pelo menos esteve perto dos mais apavorantes; se há aqueles para quem, apesar de tudo, a vida parece opaca, é porque não ousam viver e não sabem olhar.
Ce que j'admire surtout, dans la vie, c'est son encombrement formidable. Elle est pareille aux forêts tropicales où l'abondance inextricable du branchage s'oppose à la clarté du jour. L'on heurte à chaque pas faune ou flore. On ne saurait poser les yeux que sur des drames; on ne saurait marcher qu'en en créant. Nul homme qui, s'il ne les a vécus lui-même, n'ait coudoyé du moins les plus affreux; à qui si malgré tout la vie humaine paraît terne, c'est qu'il n'ose point vivre et qu'il ne sait pas regarder.
" "Il y a la réalité et il y a
les rêves; et puis il y a une
seconde réalité" (Gide, A.
"Si le grain ne meurt". Em:
Journal 1939-1949. Op.
Cit.: 362).
"(:438-39 e 485)
"l'état lyrique [...] où Diony-
sos me visitait" (: 485)
" "l'invisible réalité" (: 438)

${ }^{2}$ Schaudern, termo alemão para "tremor", é empregado por Gide para designar, em suas memórias, três experiências de infância, "iluminações" angustiadas acompanhadas pelo sentimento de desvelamento de uma realidade profunda e oculta. Essas experiências parecem anunciar sua vocação de escritor. 
- Rascunhos de Les caves du Vatican, BLJD, y893, ff.: 26.27)
" (Crônicas de jornal sobre pequenos acontecimentos. N. da T.)

* "dont les motifs restent mystérieux, échappent aux règles de la psychologie traditionnelle, et déconcer. tent la justice humaine" (Gide, A. Prefácio a “L'Affai Redureau". Em: Ne jugez pas. Paris: Gallimard 1930: 97).

- "Il y a, par-delà la logique, une sorte de psychologique cachée qui m'importe, ici, davantage" (Gide, A. "Ainsi soit-il". Em: Souvenirs et voyages. "Bibliothèque de la Pléiade". Paris: Gallimard, 2001: 993).

- “le monde n'[a] aucun besoin de [lui]" (:993)
Para mim que, há alguns anos, cansado dos livros, de olhar faço profissão, o que nem sempre é a forma mais intensa de viver, vi nascer sob meu olhar, asseguro, sucessões de acontecimentos tão estranhos, tão novos, tão retorcidos, tão cheios de galhos que, agora que é meu dever expor uma parte, tremo com o pensamento de que se formem mal no relato que desejo fazer. Só a quantidade dos acontecimentos que precisarei relatar me assombra; cada um deles daria todo um volume, se eu apenas o contasse com o tipo de comentário moral que os romancistas de hoje, creio eu, se acostumaram a acrescentar [...]. É preciso contar ou tudo, ou nada. Mas, de agora em diante, contar sem comentários.
Pour moi qui, depuis quelques ans, las des livres, fais profession de regarder, ce qui n'est pas toujours la moins intense façon de vivre, j'ai vu naître sous mon regard, je le dis, des suites d'événements si étranges, si neufs, si retors, si branchus, que, maintenant que le devoir m'incombe d'en exposer une partie, je tremble qu'ils ne se forment mal au récit que je voudrais en faire. Le nombre seul des événements qu'il faudra relater, m'effare; chacun ferait matière d'un volume, si seulement je le rapportais avec ce commentaire moral que les romanciers d'aujourd'hui ont, je crois, accoutumé d'y joindre. [...] Il faut raconter tout ou rien. Mais raconter dès lors sans commentaire."

Assim, o que interessa a Gide, e o interessaria até o final, não é exatamente o que a realidade mostra e todos podem ver, mas o que se encerra e se esconde em suas dobras. É a este desvelamento de uma realidade secreta ou oculta que o romancista se fixa, e é o que o fascinaria nos Faits-divers*. Pois os únicos “casos" que o interessam são aqueles "cujos motivos permanecem misteriosos, fogem às regras da psicologia tradicional e desconcertam a justiça humana"* - como precisamente o Caso Redureau, introduzido com essas palavras. No fim da vida, é ainda o que estimula o autor de Ainsi soit-il: "Há, além da lógica, algo como um psicológico oculto que é especialmente importante para mim aqui”*.

É ainda mais notável que, após esta declaração, ele logo em seguida constate que se retira do mundo e da vida, que "o mundo não precisa mais dele"**

No início de Les caves du Vatican, por exemplo, prevalece no autor a idéia do clandestino, da quadrilha e das manobras obscuras de uma contra-sociedade que manipula os fios de um mundo de marionetes, em que até o Papa pode ser substituído 
por um sósia sem que a cristandade perceba* . Ou, outro exemplo, o surgimento de uma realidade sensivelmente diferente daquela que o Pastor-narrador de La symphonie pastorale ( $A$ sinfonia pastoral) acredita contar motiva a ironia da narração.

Último eixo que gostaria de evidenciar aqui - mas ainda haveria muitos outros - é, de um lado, o constante interesse pedagógico de Gide pelo desenvolvimento de meninos e rapazes, e de outro a evolução de sua visão e concepção das mulheres.

Quase todas as suas obras se centram em um rapaz, de início um alter ego, depois, a partir do mítico Nathanaël, destinatário escolhido, ideal, encarnando o adolescente do futuro a quem é preciso exortar e instruir. Cada um deles vive uma aventura na medida de sua natureza e de seu apetite. A espera de Alissa será o álibi do medíocre Jérôme, enquanto um Lafcadio busca dar toda a medida a suas virtualidades. Olivier tem necessidade de um tutor afetuoso, enquanto Bernard goza de autonomia e senso de responsabilidade.

Junto a essas figuras maiores, o olhar do romancista se volta para as pequenas, interessado por elas e emocionado com sua situação e condição: o pequeno Casimir de Isabelle, o Beppo de Caves, o Boris de Les faux-monnayeurs. Sente-se com relação ao autor uma poderosa simpatia aliada a uma verdadeira curiosidade por essas figuras desfavorecidas ou marginais.

Além desse mundo masculino, há para Gide um mistério do continente da feminilidade. Por exemplo, a Geneviève de Les caves du Vatican, que é concebida tarde e chega tarde, como uma bóia salva-vidas para Lafcadio: como Gide se sente pouco à vontade para fazê-la falar e agir na grande cena final, como ele põe em sua boca palavras tiradas artificialmente de romances, que soam falso, e como, no entanto, ela o atrai, como Gide se apega a ela, ainda tentando, em suas últimas semanas de vida, captar o mistério de seu ser, de seu poder, a razão do caráter indispensável e irredutível de sua presença! Mas, até o fim, ele continuaria embaraçado, sem saber o que fazer com ela.

A mulher permanece, portanto, um continente misterioso e secreto da obra de Gide. Mulher por tanto tempo sonhada, de início vaporosa e abstrata, como Emmanuèle em Les cahiers d'André Walter; ele logo adivinha o caráter irredutível de sua presença e de um desejo que o incomoda, por não lhe possibilitar o acesso, que no entanto se manifesta apesar de tudo, até mesmo
(Cf. Goulet, A. "Dans Les caves du Vatican", colóquio "Gide na Flórida", Sarasota, 18.20 janvier 2001, a ser publicado em Bulletin des Amis d'André Gide) 
* (Gide, A. Les cahiers d'André Walter. "Bibliothèque de la Pléiade". Paris: Gallimard, 1986: 85.86)
"(Gide, A. "La Porte étroite". Em: Romans, récits et soties, œuvres lyriques, Op. cit.: 500)

na evanescente Emmanuèle, e que afirmaria mais claramente com o Diário de Alissa. Observemos como André Walter foge ao contato com Emmanuèle, mesmo em sonhos:

Timidamente [...], com medo de que você se aproxime de mim, eu me mantenho bem longe.

[...] Então você vem, apesar de tudo, e eu não posso mais fugir, e a sua mão pega a minha mão inutilmente fugitiva, depois devagar e com ternura a acaricia. [...] E você ficava de olhos baixos; eu tentava me desvencilhar, em vão, da sua mão obstinadamente terna.

E tudo isso era tão estranhamente doce que eu acordei como de um pesadelo.
Craintivement $[\ldots]$, de peur que tu ne m'approches, je m'étais mis très loin de toi.

[...] Voici que tu t'approches pourtant, et que je ne puis pas fuir, et ta main prend ma main, inutilement se dérobant, puis lentement, tendrement, la caresse. [...]

Toi, tu restais les yeux baissés; moi, je tentais de repousser, mais vainement, ta main obstinément caressante.

Et cela était si étrangement doux que je m’en suis éveillé, comme d'un cauchemar."

Diante da mulher anjo (Angèle, Emmanuèle...), a mulher perigosa, perturbadora, carnal, cujo protótipo seria a tia Lucile Bucolin. Sua mão assusta o jovem Jérôme:

[...] ela puxa meu rosto para o seu, põe o braço nu em volta do meu pescoço, desce a mão pela abertura da minha camisa, pergunta rindo se eu não sinto cócegas e a mão avança... Tenho um sobressalto $[\ldots]$ - fujo dela; $[\ldots]$ lavei, esfreguei o rosto, o pescoço, tudo que tinha sido tocado por aquela mulher.
[...] elle attire contre le sien mon visage, passe autour de mon cou son bras nu, descend sa main dans ma chemise entrouverte, demande en riant si je suis chatouilleux, pousse plus avant... J'eus un sursaut [...] - je m'enfuis; [...] lavai, frottai mes joues, mon cou, tout ce que cette femme avait touché.*

Essa mulher de carne e de desejo está presente como um polvo fantasmático e fantástico desde Le voyage d'Urien, misturada às "sereias" de "coxas cor de aço" e às "vampiras" que "sugavam a vida”. E o temor das uniões carnais se exprime por todo tipo de metáforas, como, por exemplo, quando a rainha Haiatalnefus, apaixonada pelos cavaleiros, leva-os de barca até uma gruta: 
A barca avançava por uma abertura muito estreita, que impedia a visão assim que entramos [...]. Gostaríamos de nadar naquele oceânico lugar mágico, mas nos contivemos por medo de caranguejos e lampreias. $^{3}$
La barque y pénétrait par une très étroite ouverture et qu'on ne voyait plus dès qu'on était entré [...]. Nous aurions bien aimé nager dans cette océanique féerie, mais nous n'osâmes pas nous baigner de peur des crabes et des chatrouilles.
" (Gide, A. "Le voyage d'Urien". Em: Romans, ré cits et soties, œurres lyriques, Op. cit.: 23, 29, 34)

" "assise sur le lit, les che veux défaits, presque nue, couverte seulement d'un châle déjà presque tout retombé" (Gide, A. "La Ten tative amoureuse". Em: Ro mans, récits et soties, œuvres lyriques, Op. cit.: 74).
" "une femme en peignoir béant, aux cheveux défaits" (Gide, A. "Les caves du Vatican", Em: Romans, ré cits et soties, œuvres lyri ques, Op. cit.: 782)

" “une jeune servante [aux] tétons jaillis du corset" (: 800).

\footnotetext{
* "largement échancré, selon une coutume qui me parut - dit Thésée - impudique, [laissant] les seins à l'air", "grandement incommodé [par] la très forte odeur qu s'échappait avec ses seins de son corsage" (Gide, A. "Thésée". Em: Romans, ré cits et soties, œuvres lyriques, Op. cit.: 1422, 1426 e 1428).
}

${ }^{3}$ Nesta última citação, pode-se ler uma angústia perante a "vagina dentada". Cf. Goulet, A. "Le corps fantasmé de la femme dans les fictions gidiennes". Em: Behrens, R. Galle, R. (Hrsg). Menschengestalten: Zur Kodierung des Kreatürlichen im modernen Roman, Würzburg: Königshausen und Neumann, 1995:71-82. 
- "essentiellement soumise et dévouée" (Gide, A. "Les caves du Vatican". Em: Romans, récits et soties, œuvres lyriques, Op. cit.: 787)

- "pour pouvoir mieux donner ensuite, à un tas de femmes, la conscience de leurs pouvoirs" (Gide, A. "Geneviève". Em: Romans, récits et soties, œuvres lyri ques, Op. cit.: 1369 e 1399).

" "rétroaction du sujet sur lui même" (Gide, A. Journal 1889-1939, Op. cit.: 40-41).

- "en sortant de nous, [le livre] nous change, il modifie la marche de notre vie $[\ldots]$ " (:41).

* "Il songe à sa nouvelle règle de vie, dont il a trouvé depuis peu la formule: "Si tu ne fais pas cela, qui le fera? Si tu ne le fais pas aussitôt, quand sera-ce?" (Gide, A. "Les faux-monnayeurs". Em: Romans, récits et soties, œuvres lyriques, Op. cit.: 976).
Mas há também toda uma reflexão profunda de Gide sobre o status da mulher, reflexão sobre sua autonomia e seus direitos esboçada após a Primeira Guerra Mundial. Em Les caves du Vatican, enquanto ainda se diz dela "essencialmente submissa e dedicada", o romancista estabelece uma linhagem de moças que se revoltam contra a condição que lhes reserva a sociedade: Geneviève em Les caves du Vatican, Sarah em Fauxmonnayeurs e, principalmente, a Geneviève da narrativa epônima, decidida a lutar pela emancipação das mulheres. Ela funda a liga para a "Independência feminina" e quer estudar direito "para despertar em um monte de mulheres a consciência de seus poderes"* . Com esta última obra, concebida de início como um "grande romance feminista", Gide se volta para a mulher para lançar as bases de uma sociedade que se desvencilhe de seus conformismos e preconceitos. Mas a obra sucumbe. Decididamente, a mulher não é seu continente.

\section{III}

Para terminar, algumas considerações sobre o trabalho da escrita.

No início eu dizia que a escrita era, para Gide, essencial e vital. Pois não somente ele se investe em cada uma de suas ficções, alimentando-as de suas virtualidades e dos personagens contraditórios que as habitam, mas, ao fazê-lo, é operada uma "retroação do sujeito sobre si mesmo"* que o purga e o ajuda a progredir sem se deter, a "ir mais longe", segundo um de seus lemas favoritos. Afirma ele: "ao sair de nós, [o livro ] nos muda, modifica a marcha de nossa vida $[\ldots]^{*}$.

Isto também significa que a escrita gideana caracteriza-se por uma tensão interna entre um investimento tão grande do autor que chega até a proporcionar um sentimento de despersonalização, e uma distância crítica ou irônica para dominá-la e permitir que se desengaje dela pela expressão.

Seguem-se vários corolários. Inicialmente, esta obrigação interna com que ele se sente habitado, que o manda escrever tal ou tal obra, e que ele atribui a muitos personagens, Bernard em particular. Ele sonha com sua nova regra de vida, tendo achado há pouco tempo a fórmula: "Se você não fizer isso, quem vai fazer? Se você não fizer logo, quando o fará?"*

É em nome desta obrigação íntima que escreveria principalmente Corydon, Voyage au Congo ou Retour de l'URSS. 
Em seguida, uma constante disposição para a escuta. De seus personagens, de início, contrariamente a Robert de Passavant, protótipo do mau romancista ${ }^{4}$. Mas também escuta de suas palavras, de seus ritmos, do tom, que não cessa de corrigir e ajustar para obter a enunciação mais correta possível. Este falar correto a ser atingido é o que corresponde a sua verdade interior, e não à realidade, segundo uma distinção essencial que estabelece Edouard entre a verdade da arte e a realidade da natureza:

Às vezes me parece que não há nada que eu admire tanto em literatura quanto, por exemplo, a discussão em Racine entre Mithridate e seus filhos; sabemos muito bem que pais e filhos jamais falaram daquele jeito, e no entanto (e eu deveria dizer: quanto mais é assim, mais é verdade) todos os pais e todos os filhos podem se reconhecer ali.

Por isto houve quem reprovasse em Gide as esquisitices de estilo e de expressão, uma certa afetação ou às vezes preciosismo. Um exame atento de seus rascunhos mostra que tudo isso é intencional e medido, fruto desse trabalho de "estilização" reclamado por Edouard, ou seja, da criação de um estilo que, como todos sabem desde Buffon, "é o próprio homem”* Gide sabe que a linguagem não mimetiza o mundo, mas é uma difícil conquista, exigência humana e não dom natural. Por isto temos seus rascunhos tão trabalhados e corrigidos, como nos mostra o CD-Rom da Édition génétique de Les caves du Vatican.

Finalmente, segundo a fórmula recentemente lançada por Catharine Brosman, Gide é um mestre na arte do "claro-escuro". Claridade enganosa de sua narrativa, cheia de alçapões e, sobretudo, de mistérios, formulações ambíguas, alusões discretas, profundezas ocultas.

\footnotetext{
4 "O senhor jamais daria um bom romancista. [Vous ne ferez jamais un bon romancier.]

"Por quê?" [Parce que?]

"Porque não sabe escutar." [Parce que vous ne savez pas écouter.]
}

Parfois il me paraît que je n'admire en littérature rien tant que, par exemple, dans Racine, la discussion entre Mithridate et ses fils; où l'on sait parfaitement bien que jamais un père et des fils n'ont pu parler de la sorte, et où néanmoins (et je devrais dire: d'autant plus) tous les pères et tous

\footnotetext{
" "est l'homme même" (Buffon, Discours sur le style, Paris: Hatier).
} 
" (Gide, A. "Feuillets". Em Journal 1889.1939, Op. cit.: 660)

"la vraie morale se moque de la morale" (Pascal, B. Les Pensées. Paris: Seuil, 1963: I, 4)

" "choisi [...] de devenir sa vérité" (Sartre, J.P. "Gide vivant". Em: Les Temps modernes, março de 1951 citação retomada em Situations IV, Paris: Gallimard, 1964: 89).
Todas as grandes obras de arte são de difícil acesso. [...] Este coração misterioso [da obra], não é necessário usar de obscuridade para protegê-lo de uma abordagem insolente demais; para isto, basta a clareza.
Toutes les grandes œuvres d'art sont d'assez difficile accès. [ ...] Ce cœur mystérieux [de l'œuvre], nul besoin d'obscurité pour le défendre contre une approche trop effrontée; la clarté y suffit aussi bien".*

Faz cinqüenta anos que Gide deixou a terra, mas continua a viver entre nós, a ser um dos nossos por uma obra que pouco a pouco, parece-me, encontra seu verdadeiro lugar, ao lado das maiores e mais altas, não somente por esse classicismo que ele cedo reivindicou e que lhe é reconhecido, mas principalmente por suas qualidades de moralista, no melhor sentido do termo; "a verdadeira moral zomba da moral", dizia Pascal" por importarse com o homem por inteiro, com tudo o que diz respeito a sua condição, por seu permanente cuidado com um falar verdadeiro e correto, por compreender e proporcionar compreensão, por inquietar ao deslocar questões e pontos de vista, por habitar sua obra e solicitar a reflexão do leitor. Em uma grande homenagem esboçada no dia seguinte à morte de Gide, Sartre o elogiava por ter "escolhido [...] se tornar em sua verdade"*. Que ele possa continuar a nos ajudar a encontrar a nossa, a nos tornar, como acrescentou Sartre, "em verdades novas".

Tradução

Norma Cristina Guimarães Braga 


\section{Alain Goulet}

Professor emérito de literatura francesa da Universidade de Caen, e autor de inúmeras obras sobre André Gide, entre as quais Fiction et vie sociale dans l'cuure d'André Gide(Minard, 1986), André Gide: écrire pour vivre (Corti, 2002), e o CD-Rom Édition génétique de Les caves du Vatican d'André Gide (Univ. de Sheffield \& Gallimard, 2001). Suas outras publicações são sobre a literatura francesa do século XX (Beckett, Robbe-Grillet, Sarraute, Duras, Perec, Modiano, Le Clézio, S. Germain).

\section{Resumo}

Reflexões sobre a obra de André Gide e as grandes questões que a permeiam, em uma estreita correspondência com sua vida, suas aspirações à liberação de sua sexualidade, sua luta política e privada pela liberdade e a incessante busca de uma linguagem e uma expressão próprias, construtoras de "verdades novas".

\begin{abstract}
Thoughts on the work of André Gide and the vast questions that it concerns, in a straight correspondence with his life, his aspirations towards the liberation of his sexuality, his political and private fight for freedom and the incessant quest for a language and an expression of his own, as builders of "new truths".
\end{abstract}

\section{Résumé}

Réflexions sur l'œuvre d'André Gide et les grandes questions qui la traversent, dans une correspondance étroite avec sa vie, ses aspirations à la libération de sa sexualité, sa lutte politique et privée pour la liberté et la recherche sans cesse d'un langage et d'une expression propres, constructrices de "vérités nouvelles".
Palavras-chave André Gide linguagem e romance diário e ficção

Keywords André Gide language and novel journal and fiction

Recebido em 20/06/2002 Aprovado em $12 / 07 / 2003$ 